Western University

Scholarship@Western

Aboriginal Policy Research Consortium International (APRCi)

2011

\title{
Indigenous Communities and Evidence Building
}

Holly Echo-Hawk

Follow this and additional works at: https://ir.lib.uwo.ca/aprci

Part of the Health Policy Commons

Citation of this paper:

Echo-Hawk, Holly, "Indigenous Communities and Evidence Building" (2011). Aboriginal Policy Research Consortium International (APRCi). 187.

https://ir.lib.uwo.ca/aprci/187 
This article was downloaded by: [University of Western Ontario]

On: 18 November 2012, At: 07:54

Publisher: Routledge

Informa Ltd Registered in England and Wales Registered Number: 1072954 Registered office: Mortimer House, 37-41 Mortimer Street, London W1T 3J H, UK

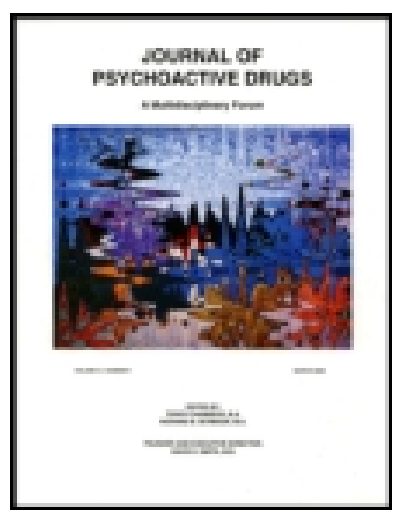

\section{J ournal of Psychoactive Drugs}

Publication details, including instructions for authors and subscription information:

http:// www. tandfonline.com/loi/ ujpd20

\section{Indigenous Communities and Evidence Building}

Holly Echo-Hawk M.S. ${ }^{\text {a }}$

${ }^{a}$ Mental Health Consultant, Echo-Hawk and Associates, Vancouver, WA, USA

Version of record first published: 22 Nov 2011.

To cite this article: Holly Echo-Hawk M.S. (2011): Indigenous Communities and Evidence Building, J ournal of Psychoactive Drugs, 43:4, 269-275

To link to this article: http:// dx.doi. org/ 10.1080/ 02791072.2011.628920

\section{PLEASE SCROLL DOWN FOR ARTICLE}

Full terms and conditions of use: http://www.tandfonline.com/page/terms-and-conditions

This article may be used for research, teaching, and private study purposes. Any substantial or systematic reproduction, redistribution, reselling, loan, sub-licensing, systematic supply, or distribution in any form to anyone is expressly forbidden.

The publisher does not give any warranty express or implied or make any representation that the contents will be complete or accurate or up to date. The accuracy of any instructions, formulae, and drug doses should be independently verified with primary sources. The publisher shall not be liable for any loss, actions, claims, proceedings, demand, or costs or damages whatsoever or howsoever caused arising directly or indirectly in connection with or arising out of the use of this material. 


\title{
Indigenous Communities and Evidence Building
}

\author{
Holly Echo-Hawk, M.S. ${ }^{\text {a }}$
}

\begin{abstract}
Indigenous populations in the U.S. and Pacific Islands are underrepresented in mental health and substance abuse research, are underserved, and have limited access to mainstream providers. Often, they receive care that is low quality and culturally inappropriate, resulting in compromised service outcomes. The First Nations Behavioral Health Association (U.S.) and the Pacific Substance Abuse and Mental Health Collaborating Council (Pacific Jurisdictions), have developed a Compendium of Best Practices for American Indian/Alaska Native and Pacific Island Populations. The private and public sector's increasing reliance on evidence-based practices (EBP) leaves many Indigenous communities at a disadvantage. For example, funding sources may require the use of EBP without awareness of its cultural usefulness to the local Indigenous population. Indigenous communities are then faced with having to select an EBP that is rooted in non-native social and cultural contexts with no known effectiveness in an Indigenous community. The field of cultural competence has tried to influence mainstream research, and the escalating requirement of EBP use. These efforts have given rise to the practice-based evidence (PBE) and the community-defined evidence (CDE) fields. All of these efforts, ranging from evidence-based practice to community-defined evidence, have a shared goal: practice improvement.
\end{abstract}

Keywords - community-defined, evidence-based, Indian, Indigenous, Native, Pacific Island, practicebased, recovery

Most communities search for ways to improve quality of care within their health delivery system. But the urgency of meeting basic human needs in Indigenous communities often leaves little time to develop the thinktank environment needed to develop evidence-building strategies. Another challenge to local Indigenous evidence building is the impact of historical, and ongoing, traumas within Indigenous communities. Dr. Maria Yellow Horse-Brave Heart developed the concept of Historical Trauma and Unresolved Grief Intervention in

The author of this article wishes to acknowledge the valuable contributions of the other Compendium authors: Jill Shepard Erickson, M.S.W., Valerie Naquin, M.A., Vijay Ganju, Ph.D.; Kathryn McCutchan-Tupua, Barbara S.N. Benavente, Jeff J. King, Ph.D., and David Alonzo.

${ }^{a}$ Mental Health Consultant, Echo-Hawk and Associates, Vancouver, WA.

Please address correspondence to Holly Echo-Hawk, M.S., EchoHawk and Associates, 16715 Leaper Road, Vancouver, WA 98686; phone: 360-571-3203,email: echohawk@ pacifier.com. the context of cultural renaissance and Indigenous grass roots movements throughout American Indian and Alaska Native communities. Dr. Brave Heart formed the Takini Network in 1992 to look at historical trauma among the Lakota/Dakota/Nakota tribes, their recent Big Foot Rides to commemorate the Wounded Knee massacre, and to provide a safe setting for ceremonial healing (Brave Heart 2003). The historical trauma and intergenerational grief of tribal communities was compared to research on the children of holocaust survivors in Europe (Fogelman 1991).

Trauma can also play a silent but large role in the ability, interest and willingness of Indigenous communities to combine the strengths of their culture with the strengths of science. For example, discussion with local universities to move toward a partnership of collaborative evidence building can bog down at the Institutional Review Board level if the agreement is not grounded in a participatory action research approach that supports the Indigenous perspective and local Indigenous need. 
Another contributor to the slow pace of Indigenous evidence building is confusion generated by the different definitions of evidence that correspond to a differing range of practices. Some of these practices, and their corresponding definitions of "evidence," include evidence-based practices, practice-based evidence, community-defined evidence, model practice, best practice, and promising practice. Each of these categories may rely on a type of evidence, and each type of evidence may have different levels of rigor as the qualifying basis. In the Indigenous service field, providers receive little education about the full range of evidence options, and often have little time to explore their applicability to service to Indigenous populations.

The scientific process itself poses limitations in regard to developing Indigenous evidence-based practices. As pointed out in Hawkins \& Walker's (2006) publication, Best Practices in Behavioral Health Services for American Indians and Alaska Natives, "empirically-based science leaves no room for the cultural context that is crucial to the success of a treatment approach within tribal communities." Much of the evidence used to document the basis for an effective intervention springs from quantitative research and controlled clinical trials, but these procedures and designs do not necessarily fit well with the circumstances that characterize many Indigenous groups.

The worldview differences between culture-driven services and science-driven evaluation is the foundation of their philosophical disconnect. Another way to understand this disconnect challenge is by examining the genesis of the cultural competence and evidence-based practice movements. The cultural competence movement was field-driven. The evidence-based practice movement was academic-driven. Further, the evidence-based practice movement was primarily promoted by academic researchers typically working with nondiverse populations (Sue 1998). Although each of these movements had their individual motivations and successes, each also had their challenges. The Road to Evidence: The Intersection between Evidence-Based Practices and Cultural Competency in Children's Mental Health (Isaacs et al. 2005) summarized the challenges of the cultural competence and evidence-based practice movements. The limitations of cultural competence movements included:

- Lack of definitional clarity and an operational framework and strategy; need for cultural competence guideposts for change

- Lack of synergy and sustained attention; need for broad system change beyond response to federal mandates and funding expectations

- Lack of uniformity of standards and crossfertilization among child serving systems; no uniform determination on the role of culture in service provision and outcome

- Need to refine culture-driven service domains and indicators in cultural competence assessment tools, develop definitions, validate cultural performance measures, develop data collection instruments that measure the influence of culture, and field testing

- Lack of evaluation and research; need for mental health research institutions to increase the number of empirical studies of the influence of cultural competence on service outcome

The limitations of evidence-based practices included:

- Inadequate inclusion of ethnic and cultural groups in evidence-based practice study samples; research on treatment effectiveness did not study significant numbers of cultural minorities, therefore the research may have limited applicability and acceptability to minority communities

- Limited resources devoted to the research of culturallyspecific practices; culture-driven practice are often developed by ethnic service providers and communitybased organizations and many of these organizations lack the capacity and resources to do more than provide services; and, in contrast, many mainstream organizations lack the cross-cultural skills to partner with minority organizations for research

- Lack of theory development about the relationships between culture, mental health disorders, and treatment; the rapidly growing population of ethnic minorities and cultural groups mandates serious exploration of the role of culture on how mental health is viewed by minority populations, the minority community view on help-seeking, and the motivation within minority communities for participation in treatment

- Limited involvement of ethnic and culturally diverse researchers; minority researchers are relatively rare in the overall field of behavioral health research, and those minorities who have chosen this field often lack cultural mentors and other supports to influence mainstream research

Over the years, a growing number of efforts have been made to bridge the evidence-based and culturalcompetence worlds. In 2003, the National Implementation Research Network of the Louis de la Parte Florida Mental Health Research Institute, with support from the Annie E. Casey Foundation, convened experts in the area of mental health and cultural competence. Their conclusions highlighted gaps between evidence-building science, and ethnic and cultural population practice (Ganju 2003).

- Particular mixes of services, known by ethnic minority communities to be effective, will not likely be reflected through research conducted using randomized-controlled trails (Chambless \& Ollendick 2001);

- Existing data sets from mainstream populations are inadequate to generalize the effectiveness of evidence-based programs to communities of color; 
- Organizational infrastructure process to support authentic involvement of diverse populations in designing, implementing, and evaluating evidencebased practices is lacking; and

- Emerging research and knowledge suggests that appropriate adjustments can be made for specific cultural groups.

Communities continue to search for ways to create local best practice by exploring a range of evidence-based, or practice-based, approaches. The approaches must not only fit well with their service population but must also fit their organizational capacity. In addition, establishing an organized approach to practice is a time-consuming process for any service provider and organizations that serve Indigenous populations encounter complex and imposing barriers.

The Compendium of Best Practices for American Indian/Alaska Native and Pacific Island Populations: A Description of Selected Best Practices and Cultural Analysis of Local Evidence Building (Echo-Hawk 2011) was developed by the First Nations Behavioral Health Association (U.S.) and the Pacific Substance Abuse and Mental Health Collaborating Council (Pacific Jurisdictions) with support from SAMHSA to explore this situation. Several of the programs and practices considered for the Compendium offer excellent examples of how to overcome these barriers (not all were selected for inclusion).

\section{INDIGENOUS COMMUNITY PERSPECTIVES ON EVALUATORS}

Many of the programs included in the Compendium reported a strong partnership relationship with their evaluator. The evaluator was an internal staff position in some cases, or was an external consultant in other cases. One program initially hired an external evaluator but it did not work well because the evaluator did not live in the community, and could only make periodic visits to the program. The program representative said the evaluator was "not in the community enough to see anything" and had no institutional knowledge of the program. The programs had several tips about their evaluation partner success. For example, they reported that the evaluator became a key part of their local team by:

- being involved in the community and participating in community events;

- increasing their knowledge of the more subtle cultural nuances of the community;

- staying alert to the dynamic of difference between the Indigenous worldview and the evaluation worldview;

- being culturally sensitive when providing technical assistance (e.g., attention to the cultural pace of conversation, cultural meeting locations, gender protocols, use of prayer);

- making a deliberate effort to be supportive rather than directive;
- adapting and using the local cultural approach to accomplishing objectives rather than imposing a model or approach used in other settings; and

- sharing results and findings in layman's terms.

Many of the programs spoke of developing long-term, positive relationships with their evaluator. In several cases, the evaluator became a type of historian for the organization. As the "keeper of their story," the evaluator held special responsibility to the program and the community, of course in partnership with the program or organizational leadership. The program representatives spoke of how the evaluator can play a valuable role in helping the program see patterns over time regarding the impact of their services.

\section{GROWING AN EVALUATION CULTURE WITHIN INDIGENOUS ORGANIZATIONS}

One important, but often overlooked, lesson learned is the fundamental need to establish an organizational culture from which evidence building can grow. The Cook Inlet Tribal Council adopted a proactive approach to the challenge of evidence-based practice development and provided a good example of the how to lay the organizational groundwork for evidence building within an Indigenous organization. Established in 1983, the Cook Inlet Tribal Council is a tribal, nonprofit organization located in Anchorage, Alaska. The Cook Inlet Tribal Council serves more than 12,000 people each year through seven program areas: Helping Hands provides assistance for individuals and families facing immediate challenges; Nurturing Families helps adults who want to become better parents; Supporting Youth helps young people reach their potential through a range of supports; Growing Graduates provide youth with the support they need to be successful; Developing Skills provides education, training, and certification programs for adults; Finding Jobs provides easy access to the career center, a one-stop resource for developing resumes, work skills, job opportunities, and job interview preparation; Promoting Business helps individuals develop their business and customer service skills through Cook Inlet Tribal Council-owned businesses; and Achieving Sobriety supports those who want life-long change through unique and successful treatment programs, all based in Alaska Native values and cultures.

Using a well thought-out and deliberate transformation process, the Cook Inlet Tribal Council shifted their paradigm of how they serve the Alaska Native service population from entitlement to responsibility and partnership. The organizational leadership insisted on a participatory role with their service participants. They believe that only an active, intentional partnership will move Alaska Native people forward in their quest for health improvement. Instead of visualizing services as a "hand out," the Cook Inlet Tribal Council perceives its role as providing a "hand 
up," in full partnership with Indigenous participants. The Cook Inlet Tribal Council mission statement, "to work in partnership with our people to develop opportunities to fulfill our endless potential", institutionalized their commitment to full partnership with the Indigenous population they serve.

Another important step was establishing an organizational leadership framework based in Indigenous tradition. The leadership framework for Cook Inlet Tribal Council is based on three values: accountability, stewardship, and transparency. Although they sound very modern, each of these concepts is deeply rooted in traditional culture. For example, in remote and weather-severe Alaska Native communities, all members of a group are accountable to each other; likewise in the Cook Inlet Tribal Council organizational culture, each staff member is accountable to coworkers and consumers. Second, Alaska Native people have long been stewards of the Earth's resources. Similarly, the Cook Inlet Tribal Council is the steward of the resources it receives and is accountable to those it serves to spend those resources well. Third, the value of transparency (that is, clarity of purpose, function, and responsibility) is embedded in Alaska Native traditional culture. From an organizational perspective, the Cook Inlet Tribal Council strives for transparent operations and fluid boundaries. They know that transparency within all of their organizational functions can result in a consistent flow of meaningful information between and among all levels.

Embedding three traditional values throughout the organization provides a good example of how traditional Indigenous beliefs can create an organizational foundation of readiness for change. For Cook Inlet Tribal Council, part of this readiness for change included an exploration of the value and role of "Native evidence." The Cook Inlet Tribal Council undertook a series of sequential steps as they began to explore the Native evidence question. The steps they took may be helpful to other community service providers who serve Indigenous populations. Their sequential steps in exploring the Native fit with evidence included:

- Start with leadership at the top; leadership needs to understand and appreciate (or be introduced to) the value of evaluation as an Indigenous nation-building strategy.

- Hire or promote culture-driven, sequential thinkers who have strong organizing and cross-cultural and cross-system communication skills to help lead the effort.

- Create an organizational culture that values and measures "outcomes"; sponsor joint discussions among Indigenous consumer, administrative, and front-line staff to talk about what works and why.

- Build on the ancient Indigenous history of strategic ally building; develop strategic partnerships with Indigenous and non-Indigenous evaluation resources for shared learning.
- Think internationally; develop alliances with other Indigenous evaluation efforts underway in other countries (e.g., Canada, New Zealand, Australia, etc.).

- Identify promising practices that are successful with Indigenous populations and create work sessions to determine the ingredients that make up why and how they are successful; hold learning sessions at Indigenous locations and at Indigenous pace.

- Partner with local Indigenous people to develop one or two culture-driven outcomes that the Indigenous community would like to see occur as the result of services.

- Develop a locally appropriate, culture-driven process for collecting the information that will best measure movement toward the Indigenous-determined outcome.

- Discuss and outline the different levels of evidence ranging from promising practices through evidencebased practices, and moving from less rigorous to more rigorous types of evidence.

- View the levels of evidence merely as an organizing framework to help Indigenous community members and service providers determine where they would like to be on the continuum of evidence building; for example, in the name of tribal sovereignty and in support of the healing value of Indigenous culture, Indigenous communities can choose if they want to become more rigorous in their evidence building or not.

- Develop a process evaluation document to summarize the successes and challenges of building evidence based outcome measures for services to Indigenous people and share these experiences with other Indigenous service providers in your region or at national Indigenous conferences.

\section{INTERNATIONAL THINKING ABOUT EVIDENCE BUILDING AND OUTCOME INDICATORS}

International communities have also given consideration to the health and wellness of Indigenous people, and the outcome indicators that could measure health and wellness improvements. Indicators relevant to Indigenous peoples are unique as they must include consideration of global issues like Indigenous rights to territories, lands and natural resources. They must consider the history of the Indigenous and non-Indigenous relationship, and the extent of external threats to the wellness of the Indigenous population. Broad considerations like these, often political and economic in nature, are just part of the considerations undertaken by a United Nations effort to explore outcome indicators appropriate to Indigenous populations.

In 2006-2007, United Nations bodies, member governments, research agencies and representatives from 
Indigenous communities explored indicators they believed were relevant to Indigenous peoples. This effort explored ways to measure status and trends in Indigenous social and economic development by using Indigenous defined and culturally appropriate indicators. The United Nations work resulted in a list of core issues and thematic areas that should be considered when creating meaningful indicators to measure status and trends in Indigenous well-being. The United Nations work provided a good summary of overarching considerations important to include in the outcome indicator development process.

In addition to the broad considerations, other indicators viewed as important by this United Nations review included the following:

- Integrity of Indigenous cultural heritage

- Respect for gender differences

- Respect for identity and nondiscrimination

- Fate control and self-determination

- Full, informed and effective participation

- Culturally-appropriate education

- Overall health

- Access to infrastructure and basic services

\section{The Wharerātā Group}

The Wharerātā Group was founded under the leadership of Sir Mason Durie, Māori and professor at Massey University in New Zealand, during a special advance meeting of the International Initiative for Mental Health Leadership (Australia 2009). The meeting included Indigenous mental leaders in policy, practice and research from Canada, United States, Australia, Samoa, and New Zealand. Today, the Wharerātā Group is a network to support Indigenous leaders working in mental health and addictions, and provides a forum for sharing successful practices for Indigenous people. The Wharerātā Group is associated with the International Initiative for Mental Health Leadership (IIMHL.)

During the founding meeting of the Wharerātā Group, the participants quickly found that they shared similar concerns regarding Indigenous mental health, including concerns that Indigenous people continue to face higher rates of mental illness and inconsistent culturally competent services from mainstream health systems. In addition, the Wharerātā Group were concerned about the low numbers of Indigenous leaders in mental health across their representative countries, and the challenges Indigenous leaders face in bridging the Indigenous and non-Indigenous fields.

The Wharerātā Declaration (Wharerātā Group 2010) provided a unique framework to support the development of Indigenous leaders in mental health and addictions. The Wharerāta Declaration, in part, asserts that the foundation of healthy Indigenous individuals, families and communities lies in the shared valuing of Indigenous knowledge. Further, the declaration states that in mental health and general health, not only are Indigenous perspectives on health worthy of inclusion, but they add value to western and medical perspectives on health.

The Wharerātā Declaration outlined five themes that underlie Indigenous contributions to health and mental health:

1. Indigeneity, which means the protection and maintenance of cultural knowledge, also known as Indigenous intelligence.

2. Best or Wise Practice, which means that in mental health, Indigenous intelligence is the starting point and mainstream knowledge is added as appropriate.

3. Best or Wise Evidence, which means that evaluation is based in the origin of the intervention; that is, if an intervention is cultural, then the evaluation methodology must be based in cultural knowledge.

4. Indigenous Leadership, which means that although change is needed at a systems level, it must be based in Indigenous intelligence; this means that the Indigenous mental health leader must be:

- Informed in both cultural and mainstream knowledges, and able to switch between the two "languages" to strengthen communication skills

- Credible with our home community/network as well as with mainstream peers

- Strategic in thought and leadership to build alliances and partnerships

- Connected to protect and strengthen networks across sectors including mainstream mental health, indigenous mental health, political and funders

- Self sustainable as we work to maintain our own work-life balance, and to build future leaders to take over for us

5. Indigenous Leadership Influence-use of our positive influence through our networks, with our peers, based in our credibility, is a strategic approach to changing systems to better serve Indigenous clients.

The Wharerātā Group continues to share successful practices and ideas as a virtual network of Indigenous leaders and shares ideas with the Wharerātā Group members, with Indigenous practitioners and leaders around the world, their partners and funders.

\section{CURRENT APPROACHES AND CONCLUSION}

Many American Indian, Alaska Native and Pacific Island communities actively search for ways to demonstrate that their culture-based or culture-assisted interventions and approaches have accomplished their intended purpose. For many Indigenous and minority communities, culturally-specific, community-driven interventions have been an important part of local practice, but the practices 
often lack systematic research and evaluation to support their effectiveness. Turning to science to assist with evaluation is complicated because scientific methodologies are developed from a worldview that differs from that of the local Indigenous communities and the marriage between science and community to develop measureable outcomes is challenging.

Many practices that served Indigenous communities took different approaches to evidence-building. Because of lack of resources, some had no way to conduct a formal evaluation of the impact of the program. Some started by counting the number of people who attend events and "measured" the success of their program by its use by the community. For example, discussion with representatives from the Historical Trauma and Unresolved Grief Intervention stated that the success of their curriculum lies primarily in the numbers of tribal communities and tribal professionals who resonate to the concept of how historical trauma impacts today's communities and used the curriculum to structure their local planning and programming efforts. Other program representatives collected basic demographic information about their clients, and some developed service satisfaction surveys for distribution. The Native American Health Center in Oakland created a blue print for their organization-wide data base (Nebelkopf \& Phillips 2004). Several other programs developed close relationships with university researchers to expand their knowledge of community-based research and advanced approaches to data analysis.

As the experience and interest progressed, some began to use satisfaction surveys on a pre and post basis. They also began to track program completion rates, but many still have concerns about the limited resources they had to collate and analysis data. Some spoke of the need for more definitive data to support the program, especially when resource challenged during lean economic times. Several were able to increase their data resources by partnering with universities or churches. For example, several community programs in the Federated States of Micronesia benefited from access to the Micronesia Seminar, a Jesuit institution that is solely committed to the development of data and educational information for the Micronesia community. In this way, small organizations did not have to have evaluation staff as part of their organization; instead, they used the research resources of the Micronesian Seminar.

Some programs began focusing on broad based indicators as ways to start measuring the impact of the services on their population of focus. Some examples of indicators they started with included increased awareness and knowledge related to substance abuse; reduction in school drop out rates; increased self esteem; and increased sense of social support.

Many of the funding sources for the programs had evaluation requirements and received evaluation technical assistance. The United States Center for Substance Abuse Prevention (CSAP) Strategic Prevention Framework State Infrastructure Grant had an established need assessment and evaluation process that was used in both Guam and American Samoa. Those Tribal programs that received U.S. Center for Mental Health Services (CMHS) Circle of Care funding also received extensive technical assistance from university-based Native evaluators. The Tribal programs that were recipients of the federal System of Care funding were required to participate in an extensive evaluation protocol and received substantial training and support from a highly experienced, and Tribal experienced, national evaluation center. While the programs that serve Indigenous communities may struggle with some aspects of national evaluation protocols because of cultural mismatch, most were able to take their evaluation experience that was tied to a funding source and use the experience and technical assistance as a launch for refinement of their own evaluation design.

Often the personal interest of a key administrator or program leader led to increased interest in the evaluation of services. Creating the time to think about what type of data could benefit the program, and how to become more organized in their approach, was a first step. Some of the programs also identified outside research or evaluation consultants to help them explore the data possibilities. One of the programs contracted with a Native evaluator to facilitate a day-long discussion on research issues in Native American communities. This was a significant discussion that helped the program link data and research to Native American cultural ways and they were then better able to develop short and long term goals for evidence-building.

Some of the best practice programs used a curriculum approach to their service, but attention to cultural fit with the community was important. For example, one of the programs purchased a curriculum but the curriculum developers objected to any changes to the materials that went beyond language translation. Another program was able to modify a data collection instrument (changing a reference from "freeway" to "river" or "bridge" instead). Another program made a modification in the length of the time designated for the information gathering to be more culturally fitting with the local culture.

Several points need attention in conclusion. First, the Cook Inlet Tribal Council team believed that every Indigenous organization has some type of evidence in play, but the organization may not be aware of the evidence they have. The Cook Inlet Tribal Council development of the Indigenous Model of Evidence-Based Effective Practice that outlined various levels was designed to not only validate Indigenous practices, but to offer a way to help communities to organize their thinking around how to document their practice in a systematic and organized manner. Second, the Wharerātā Declaration asserts that best evidence is based within the intervention. That is, 
if the intervention is clinical, then the assessment or evidence should also be based in clinical perspectives. If the intervention is cultural, then the evidence of success should be based in cultural perspectives. According to the Declaration, the sourcing of evidence from one way of knowing to assess the other does not follow cultural competence standards. Last, most believed that Indigenous people have a right and responsibility to determine the processes by which the service-related evidence base is developed, integrating not only appropriate research, but also Indigenous consumer feedback and Indigenous ways of knowing.

Indigenous communities, mental health professionals and researchers agree that better behavioral health outcomes are needed, but there has been a lack of clarity on how to build evidence in a way that includes the critical influence of culture on outcomes. The need to find a balance point between the Indigenous views of best practice and Western evidence building would be a win-win solution.

\section{REFERENCES}

Brave Heart, M.Y. H. 2003. The historical trauma response among Natives and its relationship with substance abuse: A Lakota illustration. Journal of Psychoactive Drugs 35 (1): 7-13.

Chambless, D. \& Ollendick, T. 2001. Empirically supported psychological interventions: Controversies and evidence. Annual Review of Psychology (52): 685-716.

Echo-Hawk, H., Erickson, J., Naquin, V., Ganju, V., McCutchan-Tupua, K., Benavente, B., King, J., \& Alonzo, D. 2011. Compendium of Behavioral Health Best Practices for Indigenous American Indian/Alaska Native and Pacific Island Populations: A Description of Selected Best Practices and Cultural Analysis of Local Evidence Building. Portland, OR: First Nations Behavioral Health Association.

Fogelman, E. 1991. Mourning without graves. In: A. Medvene (Ed.) Storms and Rainbows: The Many Faces of Death. Washington, DC: Lewis Press.

Ganju, V. 2003. Consensus Statement on Evidence-Based Programs and Cultural Competence. Tampa, FL: Annie E. Casey Foundation.
Hawkins, E. \& Walker, R. 2005. Best Practices in Behavioral Health Services for American Indians and Alaska Natives. Portland, OR: One Sky National Resource Center for American Indian and Alaska Native Substance Abuse Prevention and Treatment Services.

Isaacs, M.; Huang, L.; Hernandez, M. \& Echo-Hawk, H. 2005. The Road to Evidence: The Intersection of Evidence-Based Practices and Cultural Competence in Children's Mental Health. Washington, DC: Nation Alliance of Multi-ethnic Behavioral Health Associations.

Nebelkopf, E. \& Phillips, M. 2004. Healing and Mental Health for Native Americans: Speaking in Red. Walnut Creek, CA: AltaMira Press.

Sue, S. 1998. In search of cultural competence in psychotherapy and counseling. American Psychologist (53): 440-48.

Wharerātā Group. 2010. The Wharerātā Declaration. Available at http://www.indigenous-mental-health.ca/index.php/wharertdeclaration. 